\title{
Aurora A selective inhibitor LY3295668 leads to dominant mitotic arrest, apoptosis in cancer cells and shows potent preclinical antitumor efficacy
}

Jian $\mathrm{Du}^{1}$, Lei Yan $^{1}$, Raquel Torres ${ }^{2}$, Xueqian Gong ${ }^{1}$, Huimin Bian ${ }^{1}$, Carlos Marugán ${ }^{2}$, Karsten

Boehnke $^{2}$, Carmen Baquero ${ }^{2}$, Yu-Hua Hui ${ }^{1}$, Sonya C. Chapman ${ }^{3}$, Yanzhu Yang ${ }^{1}$, Yi Zeng ${ }^{1}$,

Sarah M. Bogner ${ }^{1}$, Robert T. Foreman ${ }^{1}$, Andrew Capen ${ }^{1}$, Gregory P. Donoho ${ }^{1}$, Robert D. Van

Horn $^{1}$, Darlene S. Barnard ${ }^{1}$, Jack A. Dempsey ${ }^{1}$, Richard P. Beckmann ${ }^{1}$, Mark S. Marshall ${ }^{4}$, Li-

Chun Chio ${ }^{1}$, Yuewei Qian ${ }^{1}$, Yue W. Webster ${ }^{1}$, Amit Aggarwal ${ }^{1}$, Shaoyou Chu ${ }^{1}$, Shobha

Bhattachar $^{1}$, Louis F Stancato ${ }^{1}$, Michele S. Dowless ${ }^{1}$, Phillip W. Iversen ${ }^{1}$, Jason R. Manro ${ }^{1}$,

Jennie L. Walgren ${ }^{1}$, Bartley W. Halstead ${ }^{1}$, Matthew Z. Dieter ${ }^{1}$, Ricardo Martinez $^{1}$, Shripad V.

Bhagwat $^{1}$, Emiko L. Kreklau ${ }^{1}$, Maria Jose Lallena ${ }^{2}$, Xiang S. Ye ${ }^{1}$, Bharvin K. R. Patel ${ }^{1}$,

Christoph Reinhard ${ }^{1}$, Gregory D. Plowman ${ }^{1}$, David A. Barda ${ }^{1}$, James R. Henry ${ }^{1}$, Sean G.

Buchanan $^{1}$, and Robert M. Campbell ${ }^{1}$.

Authors’ Affiliations: ${ }^{1}$ Lilly Research Laboratories, Eli Lilly and Company, Indianapolis,

Indiana; ${ }^{2}$ Eli Lilly and Company, Alcobendas (Madrid), Spain; ${ }^{3}$ Eli Lilly and Company,

Windlesham, United Kingdom. ${ }^{4}$ Ped-Hematology/Oncology, Indiana University School of

Medicine.

Running title: LY3295668 an Aurora A selective inhibitor with antitumor efficacy

Key Words: Aurora A, Kinase inhibitor, Apoptosis, Tetraploidy, Small cell lung cancer

Financial support: This work is supported by Eli Lilly and Company

*Corresponding author: Jian Du, Eli Lilly and Company, Lilly Corporate Center, DC0428,

Indianapolis, IN 46285. Phone: 317-433-3193; Fax: 317-276-1414; E-mail: du_jian@lilly.com.

This is the author's manuscript of the article published in final edited form as:

Du, J., Yan, L., Torres, R., Gong, X., Bian, H., Marugán, C., Boehnke, K., Baquero, C., Hui, Y.-H., Chapman, S. C., Yang, Y., Zeng, Y., Bogner, S. M., Foreman, R. T., Capen, A., Donoho, G. P., Van Horn, R. D., Barnard, D. S., Dempsey, J. A., ... Campbell, R. M. (2019). Aurora A-Selective Inhibitor LY3295668 Leads to Dominant Mitotic Arrest, Apoptosis in Cancer Cells, and Shows Potent Preclinical Antitumor Efficacy. Molecular Cancer Therapeutics, 18(12), 2207-2219. https://doi.org/10.1158/1535-7163.MCT-18-0529 
Conflicts of interest: All authors are current and previous Eli Lilly and Company employees and shareholders.

Word counts: 225 words in Abstract; 5317 words of text; 6 figures; 46 references.

\begin{abstract}
Although Aurora A, B and C kinases share high sequence similarity, especially within the kinase domain, they function distinctly in cell cycle progression. Aurora A depletion primarily leads to mitotic spindle formation defects and consequently prometaphase arrest, while Aurora $\mathrm{B} / \mathrm{C}$ inactivation primarily induces polyploidy from cytokinesis failure. Aurora $\mathrm{B} / \mathrm{C}$ inactivation phenotypes are also epistatic to those of Aurora A, such that the concomitant inactivation of Aurora A and B, or all Aurora isoforms by non-isoform selective Aurora inhibitors, demonstrates the Aurora B/C dominant cytokinesis failure and polyploidy phenotypes. Several Aurora inhibitors are in clinical trials for T/B-cell lymphoma, multiple myeloma, leukemia, lung, and breast cancers. Here we describe an Aurora A-selective inhibitor, LY3295668, which potently inhibits Aurora autophosphorylation and its kinase activity in vitro and in vivo, persistently arrests cancer cells in mitosis, and induces more profound apoptosis than Aurora B or Aurora A/B dual inhibitors without Aurora B inhibition-associated cytokinesis failure and aneuploidy. LY3295668 inhibits the growth of a broad panel of cancer cell lines, including small cell lung and breast cancer cells. It demonstrates significant efficacy in small cell lung cancer (SCLC) xenograft and patient derived tumor (PDX) preclinical models as a single agent and in combination with standard-of-care agents. LY3295668, as a highly Aurora A selective inhibitor, may represent a preferred approach to the current pan-Aurora inhibitors as a cancer therapeutic agent.
\end{abstract}




\section{Introduction}

The Aurora kinases are composed of three highly conserved serine/threonine kinases: Aurora A, B and C that regulate mitotic and meiotic processes (1-3). The proteins contain a highly conserved central kinase domain with a variable N-terminal domain critical for unique protein-protein interactions, and a C-terminal domain carrying a protein stability regulation motif (4).

Aurora A is critical to centrosome maturation/separation, mitotic spindle formation and mitotic spindle checkpoint activation (5-7). Aurora A mRNA/protein expression and kinase activity are cell cycle regulated, with basal level at interphase and expression/activity dramatically increased from late G2 to telophase in mitosis. The kinase activity requires Aurora A autophosphorylation at Thr288 in the activation loop. Aurora A associates with centrosomes at interphase cells, as well as with mitotic spindle in mitosis (8). Aurora A regulates mitotic progression by interacting with and phosphorylating multiple mitotic kinases, including Targeting Protein for Xklp2 (TPX2), p53, Large Tumor Suppressor Kinase 2 (LATS2), Rhoassociated, coiled-coil-containing protein kinase (p160ROCK), and others (8-11).

Aurora B controls chromosome alignment in mitosis and cytokinesis as a catalytic unit in the chromosome passenger complex which also contains Survivin, Borealin, and INCENP (1214). Similar to Aurora A, Aurora B expression and localization are cell cycle regulated, with expression and kinase activity peaking at mitosis and localization at kinetochores and centromeres from prophase to metaphase and then relocating to the cleavage furrow and midbody during cytokinesis. Meanwhile Aurora B kinase activity requires phosphorylation at Thr232 in the activation loop so that it can phosphorylate histone H3 at Ser10, and other 
substrates for chromosome condensation and spindle checkpoint $(13,15)$. Aurora $\mathrm{C}$ expression is restricted to the testis, and functionally mimics Aurora B (16).

Although the three Aurora kinases share high sequence similarity, especially at the kinase domain, they function distinctly in cell cycle progression (17). Aurora A is a mitotic kinase whose depletion primarily leads to mitotic spindle formation defects and consequently prometaphase arrest in human cancer cell lines, evidenced by the increase of histone H3 Ser10 phosphorylation as a mitotic marker. Aurora B/C function as chromosome passenger proteins such that kinase inactivation primarily induces polyploid cells. This ploidy is caused by cytokinesis failure, as evidenced by the failure of daughter cell separation and the Aurora Bmediated inhibition of histone Ser10 phosphorylation (18-20). Aurora B/C inactivation phenotypes are also epistatic to these of Aurora A. Concomitant inactivation of Aurora A and B, or all Aurora isoforms, demonstrates the Aurora B/C dominant cytokinesis failure and polyploidy phenotypes. Polyploidy and subsequent chromosome segregation error-induced genomic instability are potential mechanisms of tumorigenesis and drug resistance. Thus, Aurora B/C inhibitory activity may counter the beneficial effects of Aurora A inhibition and should be avoided with a selective Aurora A inhibitor.

Although more than a dozen of inhibitors have been developed, e.g. MLN8237 (alisertib), AZD1152 (barasertib), and others (21-25), most are either pan-Aurora or Aurora B/C inhibitors (26). As we show here, the most advanced Aurora inhibitor alisertib (MLN8237) has narrow Aurora A vs Aurora B selectivity, and at reported clinically efficacious concentrations (27), the Aurora B phenotype would dominate (27). Here we report development of a highly Aurora A selective kinase inhibitor, LY3295668, which potently inhibits proliferation in a broad panel of 
cancer cell lines, induces apoptosis, and is highly efficacious in vivo, e.g., in SCLC and other xenograft and PDX preclinical tumor models.

\section{Materials and Methods}

Cell lines and antibodies NCI-H446, NCI-H69 (both from small cell lung carcinoma), HeLa (cervical adenocarcinoma), Calu6, NCI-H358 (both from lung carcinoma), and Detroit 562 (pharyngeal carcinoma) were purchased from ATCC first in 2012 and later as needed. The panel of cell lines tested in Figure 4 is listed in the Supplementary Information. The cell lines were pathogen tested and authenticated by short tandem repeat (STR)-based DNA profiling. All cell lines were cultured in conditions recommended by vendors at $37^{\circ} \mathrm{C}$ with or without $5 \% \mathrm{CO}_{2}$ in a humidified atmosphere and used within 2 months from thaw. Growth curves were determined for all cell lines. Cell densities were optimized to achieve robust cell growth during assays.

The following antibodies against corresponding proteins were purchased and used according to the manufacturer's instruction: $\alpha$-tubulin, Centrin 1 were from Abcam; actin, $\beta$ tubulin, Aurora A P-Thr288, Aurora B, P-AuroraA/B/C (P-Thr288/Thr232/Thr198, respectively), E-cadherin, vimentin, Sox2, cyclin B1, cleaved PARP and Histone H3 were from Cell Signaling; Histone H3 P-Ser10 was from EMD Millipore, Aurora A was from R\&D Systems; $\beta$-tubulin, actin and glyceraldehyde-3-phsophate dehydrogenase (GAPDH) were from Sigma and Aldrich; horseradish peroxidase (HRP)-conjugated anti-rabbit and anti-mouse immunoglobulin G (IgG) were from GE Healthcare; and goat anti-mouse IgM Alexa Fluor 488, anti-mouse-Alexa Fluor-647, anti-rabbit-Alexa Fluor-488, and Hoechst 33342 from Thermo Fisher Scientific. The immunofluorescence microscopy was done with Leica DMI6000B or Zeiss LSM880 microscopes. For quantification of P-AurA and P-H3 in mitotic cells, images were 
acquired with the $40 \mathrm{X}$ water objective of an Opera Phenix and analyzed using Columbus software (Perkin Elmer, Waltham, MA).

Test compounds LY3285668 was synthesized at Lilly Research Laboratories chemistry labs (Example 1 in ref. 28). MLN8237 (LI-R034) was purchased from Shanghai ChemPartner Co. Ltd.. AZD1152 (HM5015062) from Hutchison MediPharma Ltd., flavopiridol from AmFineCom, Inc. (Petersburg, VA). TGF $\beta$ was from R\&D Systems (Minneapolis, MN) and

SB431542 from Sigma-Aldrich (St. Louis, MO). All compounds were dissolved in DMSO as 10 $\mathrm{mM}$ stock solution for in vitro assays. For in vivo animal studies, LY3295668 was formulated as a solution in 20\% 2-hydroxypropyl-beta-cyclodextrin (HPBCD) in 25mM phosphate buffer $\mathrm{pH}$ 2, adjusted with hydrochloric acid.

Aurora A, Aurora B enzymatic and kinase profiling assays For details, see the Supplementary Information.

Cell and tumor lysate preparations For details, see the Supplementary Information.

Aurora A inhibition by Aurora A P-Thr288 MSD and Aurora B inhibition by Histone H3

P-Ser10 inhibition (1 hour) high throughput cell-based assays For details, please see the Supplementary Information.

Mitotic arrest phenotypic and cell proliferation inhibition by histone H3 P-Ser10 and DNA content multiplexing ( 24 hours) cell-based assay See the Supplementary Information and [40] for details. 
Aurora A P-Thr288 and Aurora B histone H3 P-Ser10 in vivo target inhibition assays NCI-

H446 xenograft tumor lysates were used for in vivo target inhibition (IVTI). For details, see the Supplementary Information.

Cell proliferation and apoptosis assays See supplementary Information.

Epithelial to mesenchymal transition (EMT) and cancer cell stemness assays See

Supplementary Information and (29).

Antitumor growth efficacy with small cell lung cancer (SCLC) xenograft, PDX and other

tumor models All in vivo studies were performed according to the Institutional Animal Care and Use Protocols of the party or provider conducting the experiments. NCI-H446, NCI-H69 and Detroit 562 xenograft and the small cell lung cancer (SCLC) patient-derived tumor (PDX) models (in Oncotest GmbH, Charles River Laboratories, Freiburg, Germany) were used. For details, see Supplementary Information.

Western blot and Immunofluorescence analysis See Supplementary Information.

Flow Cytometry See Supplementary Information.

\section{Results}

\section{LY3295668 is a potent Aurora A selective inhibitor}

LY3295668 ((2R,4R)-1-[(3-chloro-2-fluoro-phenyl)methyl]-4-[[3-fluoro-6- [(5-methylIH-pyrazol-3-yl)amino]-2-pyridyl]methyl]-2-methylpiperidine-4-carboxylic acid) was identified during a medicinal chemistry program seeking to discover highly selective inhibitors of Aurora A kinase (Fig. 1A) (28). It is a reversible ATP competitive inhibitor with high aqueous solubility at $1.89 \mathrm{mg} / \mathrm{ml}$. It also shows excellent physiochemical properties with $\operatorname{LogD}(\mathrm{pH} 7.4)$ of 2.38 and 
measured fraction unbound of $1.0 \%, 1.1 \%, 1.4 \%$, and $4.5 \%$ in human, dog, rat, and mouse sera, respectively.

LY3295668 potently inhibited Aurora A and showed excellent kinase selectivity in binding of a panel of 489 protein kinases in vitro, and carries significant binding activity for only 3 other protein kinases with $\mathrm{IC}_{50}$ s less than $0.1 \mu \mathrm{mol} / \mathrm{L}$ (Fig. 1B). Enzymatically LY3295668 showed remarkable selectivity against Aurora B (1,339-fold. Fig. 1C left). In NCI-H446 cells, LY3295668 was a potent $\left(\mathrm{IC}_{50}=0.00059 \mu \mathrm{mol} / \mathrm{L}\right)$ inhibitor on Aurora A kinase autophosphorylation at Thr288 (Fig. 1C mid). Aurora B inhibition potency, as determined by histone H3 Ser10 phosphorylation, was very poor $\left(\mathrm{IC}_{50}=1.42 \mu \mathrm{mol} / \mathrm{L}\right)$ (Fig. 1C middle), indicating a >2,000-fold selectivity of Aurora A over Aurora B in this cell-based assay. Consistent with LY3295668 Aurora A inhibitory activity, 24 hours treatment led to an increase in histone H3 Ser10 phosphorylation (mitotic arrest) as well as in G2/M DNA content (Fig. 1C right) in HeLa cells. Accordingly, NCI-H446 and HeLa cell proliferations were inhibited (Fig. $1 \mathrm{C}$ right and Supplementary table 1). The correlation of Aurora A biochemical $\mathrm{IC}_{50}$ with P-H3 elevation, 4N DNA content increase, and cell proliferation inhibition indicates that LY3295668 Aurora A inhibition leads to mitotic arrest as well as cell proliferation inhibition.

Using a chemoproteomics platform (KiNativ) (30) to detect the compound kinase binding profile in NCI-H446 cancer cells, LY3295668 treatment at $1 \mu \mathrm{mol} / \mathrm{L}$ for 24 hours demonstrated an excellent Aurora A potency with inhibition efficiency at 98\%, as well as kinase selectivity with only one other kinase (EphA2) showing significant inhibition (92\%) among 203 kinases tested (Supplementary table 2). Under this condition, PLK1, Aurora B and EGFR kinase binding increased $256 \%, 265 \%$ and $851 \%(\mathrm{n}=2)$, respectively. Both PLK1 and Aurora B expression are 
cell cycle regulated, and it is expected that they would increase dramatically in mitosis (Supplementary table 2), indicating LY3295668 treatment induces G2/M arrest.

We further used the KiNativ chemoproteomics platform to examine the LY3295668 kinase inhibition profile in vivo with the NCI-H446 xenograft model. When the animals were treated at $50 \mathrm{mg} / \mathrm{kg}$ once-a-day (QD) for 3 hours, only Aurora A and Aurora B showed evidence of significant inhibition out of 195 kinases detectable (Supplementary Fig. S1A left. Supplementary Table 3). When mice were treated with LY3295668 at $50 \mathrm{mg} / \mathrm{kg}$ twice-a-day (BID) (at 0 and 12 hours) and then tumors collected at 24 hours, the compound only inhibited Aurora A significantly, while PLK1, AURKB, and three other kinase expression increased significantly (Supplementary Fig. S1A right), again indicating LY3295668 treatment in vivo led to Aurora A inhibition-induced mitotic arrest. In the mouse spleen, LY3295668 treatment at 50 mg/kg QD for 3 hours only significantly inhibited Aurora A (Supplementary Fig. S1B. Supplementary Table 4). Two treatments of LY3295668 (50 mg/kg BID, at 0 and 12 hours) demonstrated again Aurora A is the only kinase significantly inhibited and a Serine/ThreonineProtein Kinase A-Raf is the only kinase with expression significantly increased (Supplementary table 4). Taken together, LY3295668 consistently demonstrates selective Aurora A inhibition in vitro and in vivo.

Several different Aurora A and Aurora B kinase substrates in cells have been identified and used to characterize Aurora kinase inhibitors (26). Here we are the first to use an Aurora A P-Thr288 inhibition assay to screen for an Aurora A selective inhibitor. Pairwise analysis from 2940 compounds from our structure-activity relationship (SAR) library indicates that Aurora A cell-based P-T288 inhibition is most highly correlated with Aurora A enzymatic assay not Aurora B (Spearman's $\rho=0.7264$; Supplementary Table S5). The more revealing correlation 
comes from multiple linear regression analysis. For Aurora A cell assay (Fig. 1D left), improving Aurora A biochemical potency 10-fold (1 log unit) would have an expected improvement 10 fold ( $\log$ Aurora A has Estimate of $10^{1.083}$ ) in Aurora A cell potency, while Aurora B biochemical 10-fold improvement can only contribute 1.6 fold ( $\log$ Aurora B has Estimate of $10^{0.202}$ ). For Aurora B cell-based activity (Fig. 1D mid), Aurora A enzymatic activity potency increase does not contribute at all $\left(10^{-0.043}\right)$, while 10 fold Aurora B enzymatic potency increase contributes to 5 fold increase in the Aurora B cell potency $\left(10^{0.639}\right)$. So both pairwise and multiple regression correlation analyses support our flowscheme to identify Aurora A selective inhibitors (Fig. 1D and Supplementary Table S5).

Aurora $\mathrm{A}$ and $\mathrm{B}$ inhibition are not equal in inducing mitotic arrest (Fig. 1D right): improving Aurora A biochemical potency 10-fold contributes to mitotic arrest 2.9 fold $\left(10^{0.457}\right)$ while Aurora B only 1.9 folds $\left(10^{0.268}\right)$. The data indicates that Aurora A inhibition was much more effective in mitotic arrest induction, while Aurora B inhibition induced endoreduplication and polyploidy phenotype may interfere with the mitotic arrest phenotype.

To determine the Aurora A inhibition potency required inducing significant cell proliferation inhibition and thus significant anti-tumor efficacy in vitro and in vivo, a statistical analysis was performed which indicates that $90 \%$ Aurora A inhibition (Aurora A P-T288 IC 90 ) can effectively induce cell proliferation inhibition as well as mitotic arrest (Supplementary Fig. $\mathrm{S} 2)$.

\section{Aurora A selective inhibition by LY3295668 produces mitotic arrest and apoptosis in} cancer cells. 
The potency and selectivity of LY3295668 against Aurora A translated to mitotic arrest measured by histone H3 P-Ser10 marker and an increase in 4N DNA content in HeLa, NCIH446, Calu6 and other tumor cell lines (Fig. 1B, Fig. 2A left and Supplementary Fig. S3). Several Aurora inhibitors are being tested clinically, notably alisertib (MLN8237) and barasertib (AZD1152) $(21-23,25)$. Each of these Aurora inhibitors was compared to LY3295668 in cellbased assays (Fig. 2). Alisertib is an Aurora A/B dual inhibitor with approximately 16-fold Aurora A selectivity vs. Aurora B in cell-based assay (Fig. 2A mid). While mitotic arrest from LY3295668 treatment was still evident up to $20 \mu \mathrm{mol} / \mathrm{L}$ (the highest tested concentration), alisertib only showed Aurora A selective inhibition between 0.05 to $0.25 \mu \mathrm{mol} / \mathrm{L}$, but exhibited Aurora B-related P-H3 inhibition at concentrations above $0.25 \mu \mathrm{mol} / \mathrm{L}$ (Fig. 2A middle). Barasertib also demonstrated an Aurora B selective inhibitor dominated phenotype (Fig. 2A right).

All three Aurora inhibitors potently inhibited HeLa cell proliferation (Fig. 2B, left). LY3295668 also demonstrated potent apoptosis induction with significant Caspase 3/7 increase reaching maximal at $0.087 \mu \mathrm{mol} / \mathrm{L}$ and higher (Fig. $2 \mathrm{~B}$ right), correlating to its Aurora A inhibition, mitotic arrest, and cell proliferation inhibition potency (Fig. 2A left). In contrast, alisertib showed most dramatic apoptosis induction only from 0.087 to $0.250 \mu \mathrm{mol} / \mathrm{L}$, matching its Aurora A selective cell activity range (Fig. 2A middle). At concentrations of Alisertib shown to be dominated by effects of Aurora B inhibition $(>0.25 \mu \mathrm{mol} / \mathrm{L})$, the apoptosis induction actually slightly decreased (Fig. 2B right). Barasertib did not induce considerable apoptosis, reflected by less CASP3/7 induction (Fig. 2B right).

The cell growth inhibition and apoptosis induction difference among LY3295668 and other Aurora inhibitors $(2.2 \mu \mathrm{mol} / \mathrm{L})$ can also be observed from cell morphology images 
(Supplementary Fig. S4) taken from the same cell culture plates used for Incucyte quantitation in

Fig. 2B. The majority (96.4\%) of HeLa cells were killed by LY3295668 showing CASP3/7

positivity (green dots). However, there were still significant numbers of surviving cells showing enlarged/multi-nuclei and cytoplasm in alisertib or barasertib treatment, indicating they had gone through endo-reduplication and cytokinesis failure mediated by Aurora B inhibition (Supplementary Fig. S4).

Immunofluorescent staining of HeLa cells treated with $1 \mu \mathrm{mol} / \mathrm{L}$ of LY3295668 clearly indicates mitotic arrest at prometaphase with abnormally shortened microtubule spindle network, disorganized arrays of microtubules ( $\beta$-tubulin staining and Aurora A staining, which localizes to mitotic spindle and centrosomes), as well as misaligned condensed chromosomes (DAPI staining) (Fig. 3A upper and mid). LY3295668 treatment also inhibited Aurora A P-Thr288 (PAurA) staining at 94\% ( \pm 0.468$)$, with only a minor effect on histone H3 P-Ser10 (P-H3, 16\% \pm 0.2093 ), consistent with its Aurora A selective inhibition (Fig. 3A upper and mid. Fig. 3B). Alisertib treatment also arrested cells in mitosis with disarrayed microtubule spindle and misaligned chromosomes, but abolished both Aurora A P-Thr288 (95\% \pm 0.433$)$ and histone H3 P-Ser10 (93\% \pm 0.313$)$ staining. This is indicative of an Aurora A/B dual inhibition phenotype (Fig. 3A upper and mid. Fig. 3B). Although the gross network of mitotic spindle was near normal, barasertib treatment led to misaligned chromosomes as well as corrupted mitotic spindle (Fig. 3A upper and mid). Barasertib inhibited histone H3 P-Ser10 (90\% \pm 4.054$)$, but only marginally on Aurora A P-Thr288 (21\% \pm 2.976$)$, representative of an Aurora B dominant phenotype (Fig. 3A upper and mid. Fig. 3B).

PLK4 inhibition was also observed with LY3295668 (Fig. 1C) and can produce mitotic arrest. To distinguish between the Aurora A vs PLK4 inhibition-induced mitotic phenotype, cells 
were stained with Centrin 1 since centriole duplication is PLK4 dependent (31). Neither LY3295668, nor alisertib or barasertib perturbed centriole duplication and maturation with duplicated Centrin staining localized at the center of centrosomes in all the mitotic cells (Fig. 3A bottom). The data indicates that although LY3295668 may inhibit PLK4 enzyme activity in vitro, this activity did not translate into significant inhibition of PLK4 in cells (Fig. 3A bottom).

Western blot analysis further revealed the Aurora A vs Aurora B inhibition difference on mitotic arrest and apoptosis (Fig. 3C). At 0.25, 1 and $5 \mu \mathrm{mol} / \mathrm{L}, \mathrm{LY} 3295668$ treated cells for 24 hours showed Aurora A, Aurora B, histone H3 P-Ser10, and cyclin B1 increases in a dosedependent manner, indicating it effectively induced mitotic arrest (Fig. 3C left). While there was a transient increase in the expression of these endpoints by alisertib at $0.25 \mu \mathrm{mol} / \mathrm{L}$ (Aurora $\mathrm{A}$ inhibition), the increases were quickly lost due to transition to an Aurora B inhibition dominant phenotype at concentrations $>0.25 \mu \mathrm{mol} / \mathrm{L}$. Cyclin B1 levels decreased from those at 0.25 $\mu \mathrm{mol} / \mathrm{L}$ to those at 1 and $5 \mu \mathrm{mol} / \mathrm{L}$ correlated with its cytokinesis defects with Aurora B inhibition, since cyclin B1 degradation is cell cycle regulated toward telophase and cytokinesis. Barasertib as an Aurora B selective inhibitor did not show these target gene expression increase, and quite that opposite, it induced histone H3 P-Ser10 decrease from its potent Aurora B kinase inhibition (Fig 3C left). LY3295668 exhibited dose-dependent PARP cleavage (apoptosis induction) across the concentration range tested $(0.25$ to $5 \mu \mathrm{mol} / \mathrm{L})$, while alisertib induced apoptosis dose-dependently up to $0.25 \mu \mathrm{mol} / \mathrm{L}$ (most Aurora A selective concentration) which then decreased at 1 and $5 \mu \mathrm{mol} / \mathrm{L}$ (Aurora B inhibition), and barasertib only induced moderately (Fig. 3C). Longer treatment for 48 hours showed similar trend (Fig. 3C right). 
Several recent studies show Aurora A functions in EMT and tumor stemness (32-34). We tested whether LY3295668 could also prevent EMT and reduce cancer stemness in a validated model cell line, NCI-H358 (29). As previously demonstrated, TGF $_{\beta}$ inhibitor SB431542 reversed the $\mathrm{TGF}_{\beta}$-induced epithelial marker E-cadherin decrease (Fig. 3D). LY3295668, but not alisertib or barasertib, was able to partially prevent the $\mathrm{TGF}_{\beta}$ induced E-cadherin decrease at $0.1 \mu \mathrm{mol} / \mathrm{L}$ (Fig. 3D). Mesenchymal marker vimentin also showed a similar trend as seen with E-cadherin, albeit to a lesser degree (Supplementary Fig. S5). LY3295668 and alisertib inhibited Sox2 expression at the same concentration (Fig. 3D), indicating Aurora A inhibitors can reduce cancer cell stemness. However, Aurora B inhibitor barasertib did not cause a significant Sox2 decrease at the same concentration (Fig. 3D).

The Aurora A vs Aurora B selectivity of these compounds also impacted genomic stability as determined by flow cytometry analysis (Fig. 3E). LY3295668 induced strong G2/M arrest after 24 hours in HeLa cells (4N peak). The mitotic arrest persisted up to 48 hours without significant progression to $8 \mathrm{~N}$ DNA content (tetraploid from the second round of genome replication). Although both alisertib and barasertib initially caused mitotic arrest by 24 hours treatment, they accumulated tetraploid $(8 \mathrm{~N})$ cells after 48 hours treatment (two doublings for HeLa cells) through endo-reduplication and cytokinesis failure; a profile attributed to Aurora B inhibition. These polyploid cells can survive multiple rounds of endo-reduplication without fully engaging apoptosis or other cell death pathway activation, which explains the surviving cells in Supplementary Fig. S4.

\section{LY3295668 inhibits SCLC and breast cancer cell viability}


LY3295668 showed significant inhibition of cancer cell viability across a panel of 80 tumor lines (Fig. 4), mostly from breast and lung cancers. The potency of LY3295668 in cell lines ranged from $\mathrm{IC}_{50}$ single-digit nmol/L to greater than $20 \mu \mathrm{mol} / \mathrm{L}$ (Fig. 4A). 55 out of 80 $(68 \%)$ cell lines displayed significant sensitivity $\left(\mathrm{IC}_{50}<1 \mu \mathrm{mol} / \mathrm{L}\right)$ to $\mathrm{LY} 3295668$ with an average $\mathrm{IC}_{50}$ of $0.048 \mu \mathrm{mol} / \mathrm{L}$ (Fig. 4A). 28/34 (82\%) of breast, as well as 18/27 (67\%) of lung cancer cell lines, are sensitive to LY3295668 treatment and have $\mathrm{IC}_{50}$ s below $1 \mu \mathrm{mol} / \mathrm{L}$. The average $\mathrm{IC}_{50} \mathrm{~s}$ were 0.039 and $0.034 \mu \mathrm{mol} / \mathrm{L}$, respectively, for the sensitive breast and lung panels (Fig. 4B and 4C). In breast cancer cells, triple negative breast cancer (TNBC) was the most sensitive subtype with average $\mathrm{IC}_{50} 0.164 \mu \mathrm{mol} / \mathrm{L}$, and 13/15 (87\%) lines had $\mathrm{IC}_{50}$ below 1 $\mu \mathrm{mol} / \mathrm{L}$, while luminal was the most insensitive with an average $\mathrm{IC}_{50} 3.653 \mu \mathrm{mol} / \mathrm{L}$ and $13 / 19$ (68\%) had $\mathrm{IC}_{50}$ less than $1 \mu \mathrm{mol} / \mathrm{L}$ (Fig. 4B). In lung cancer cells, small cell lung cancer (SCLC) was the most sensitive tumor type with an average $\mathrm{IC}_{50}$ of $0.016 \mu \mathrm{mol} / \mathrm{L}$ and all $6(100 \%) \mathrm{SCLC}$ cell lines were sensitive to LY3295668 (Fig. 4C). 12/21 (57\%) of NSCLC were sensitive to LY3295668 with an average $\mathrm{IC}_{50}$ of $4.694 \mu \mathrm{mol} / \mathrm{L}$ (Fig. 4C).

A series of 10 compounds with Aurora A and/or Aurora B activity were tested in a bone marrow colony formation assay to better understand the heme toxicity relative Aurora kinase selectivity. LY3295668 showed an $\mathrm{IC}_{90}$ of $1.4 \mu \mathrm{mol} / \mathrm{ml}$, while alisertib and barasertib gave $\mathrm{IC}_{90} \mathrm{~s}$ at 0.2 and $0.1 \mu \mathrm{mol} / \mathrm{ml}$, respectively. Multiple regression analysis indicates that human bone marrow cell inhibition was correlation with Aurora B cell potency, but not Aurora A (Supplementary Fig. S6). This would suggest that the heme toxicity observed in rodents and clinically (alisertib, barasertib) may be driven by the Aurora B activity. As such, an Aurora A selective inhibitor might be better tolerated (also see 43). 


\section{LY3295668 is a very potent Aurora A inhibitor in vivo.}

LY3295668 demonstrated potent Aurora A inhibition in vivo in the NCI-H446 xenograft model using nude mouse and rat (Fig. 5A) at 3 hours after oral dosing. At $30 \mathrm{mg} / \mathrm{kg}$ oral dosing in mice, LY3295668 also showed persistent Aurora A target inhibition (>90\% P-Aurora A inhibition) for more than 8 hours and induced significant mitotic arrest as indicated by increases in mitotic maker histone H3 Ser10 phosphorylation (Fig. 5B left). At 50 mg/kg, LY3295668 effectively inhibited Aurora A >90\% for 12 hours (96.0, 95.1, 94.5, 90.7, and 77.5\% at 1, 4, 8, 12, and 24 hours, respectively). Correspondingly, mitotic arrest persisted up to 16 hours postdosing with histone H3 P-Ser10 increasing by 237, 323, 330, 245, and 328\% at 1, 4, 8, 12, and 24 hours, respectively. LY3295668 has a calculated Threshold Effective Dose $\left(\mathrm{TED}_{50}\right.$ : dose that produces an effect equal to $50 \%$ P-AurA inhibition) at $2.13 \mathrm{mg} / \mathrm{kg}$ and Threshold Effective Concentration $\left(\mathrm{TEC}_{50}\right.$ : concentration that produces an effect equal to $50 \%$ P-AurA inhibition) of $0.07 \mu \mathrm{mol} / \mathrm{L}$. We estimated that with twice daily (BID) dosing schedule, a dose of $30 \mathrm{mg} / \mathrm{kg}$ might be expected to achieve $>90 \%$ Aurora A target inhibition for more than 16 hours daily, while a dose of $50 \mathrm{mg} / \mathrm{kg}$ would achieve this level of target engagement for the entire dosing period. At exposures comparable to those in the mouse, a $5 \mathrm{mg} / \mathrm{kg}$ oral dose in rats, LY3295668 showed persistent Aurora A target inhibition and a corresponding histone H3 P-Ser10 increase (Fig. 5B, right).

LY3295668 at these doses did not inhibit histone H3 P-Ser10 at the 1-hour time point (Fig. 5B), indicating it did not show Aurora B inhibition in xenograft tumors. Taken together with the previous kinase profiling data (Fig. 1 and Supplementary Fig. S1), LY3295668 consistently demonstrated that it is a potent and selective Aurora A inhibitor in vivo. 


\section{LY3295668 demonstrates potent and durable responses in preclinical tumor models}

Inhibition of cell proliferation inhibition by LY3295668 was time-dependent, i.e. potency increased with longer incubation time (4 to 48 hours) and maximal inhibition reached after 24-48 hours (Supplementary Table S1 and Fig. S7). After 48 hours of LY3295668 treatment, proliferation $\mathrm{IC}_{50} \mathrm{~s}$ were $0.090 \pm 0.021(\mathrm{n}=2), 0.108 \pm 0.034(\mathrm{n}=2)$, and $0.076 \pm 0.033$ $(\mathrm{n}=2) \mu \mathrm{mol} / \mathrm{L}$, respectively, in NCI-H446, HeLa and Calu6 cells (Supplementary Table S1). The time-dependent cell proliferation inhibition in combination with the notion that $90 \%$ phosphoAurora A inhibition was needed (Supplementary Fig. S2) enabled us to design an optimized in vivo efficacy schedule. We subsequently conducted in vivo efficacy studies by achieving $>90 \%$ phospho-Aurora A inhibition for at least 16 hours/day $(30 \mathrm{mg} / \mathrm{kg}$ ) or 24 hours/day $(50 \mathrm{mg} / \mathrm{kg})$ in mice (Fig. 6A and B).

LY3295668 demonstrated significant tumor growth inhibition in SCLC NCI-H446 xenograft mode in a dose-dependent manner (Fig. 6A left). Tumors treated with $30 \mathrm{mg} / \mathrm{kg}$ LY3295668 regrew once dosing had stopped, while the tumors receiving $50 \mathrm{mg} / \mathrm{kg}$ LY3295668 did not show significant re-growth until 14 days post dosing (day-55 total duration, Fig. 6A left). LY3295668 was well tolerated, with no significant body weight loss in the study.

We varied dosing schedule to understand the duration of LY3295668 dosing needed to reach durable efficacy in SCLC NCI-H69 xenograft model. LY3295668 at $50 \mathrm{mg} / \mathrm{kg}$, dosed either as $(\mathrm{BIDx} 7$, rest 14$) \times 2,(\mathrm{BIDx} 14$, rest 7$) \times 2$, or $(\mathrm{BIDx} 21) \times 2$ schedules, all produced significant tumor growth inhibition (Fig. 6A mid). Although the effect of (BIDx7, rest 14) schedule did not persist after dosing stopped, both (BID14, rest 7) and BIDx21 dosing schedules similarly produced sustained tumor growth inhibition; lasting more than 40 days (109-day total 
duration) post-dosing (Fig. 6A middle). We also tested comparable daily dose scenarios by dosing LY3295668 at 90 mg/kg BIDx7, 50 mg/kg BIDx14, or 30 mg/kg BIDx21 (Fig. 6A right). The results confirmed that constant, complete target inhibition (50 mg/kg BIDx14) produced the most robust anti-tumor efficacy (Fig. 6A right) that persisted for at least 40 days post-dosing (day-80 total duration). Should a dosing holiday be required, LY3295668 administered at concentrations achieving $>90 \%$ Aurora A inhibition on a 14-day-on/7-day-off schedule would still be expected to reach maximal efficacy in SCLC (Fig. 6A).

We further demonstrated LY3295668 anti-tumor efficacy using SCLC Patient-Derived Xenografts (PDX) models. In LXFS538, LY3295668 treatment induced $61.1 \%$ of tumor regression at day-56 of treatment while the standard-of care (Etoposide + Cisplatin) was only moderate at $43.1 \%$ tumor growth inhibition (Fig. 6B left). When there was a significant tumor regrowth from one of the 5 tumors at day-70, LY3295668 re-treatment at $50 \mathrm{mg} / \mathrm{kg}$ showed tumor regression again (Fig. 6B left). In LXFS2156, LY3295668 treatment at $50 \mathrm{mg} / \mathrm{kg}$ BIDx28 showed $97.2 \%$ of tumor growth inhibition while the standard-of-care did not show any significant tumor inhibition (Fig. 6B right). However, the tumor inhibition in LY3295668 treated group did not persist beyond dosing period (Fig. 6B right).

Efficacy of LY3295668 was also explored in combination with various standards of care. In LXFS2156, LY3295668 at $40 \mathrm{mg} / \mathrm{kg}$ showed significant efficacy, while SoC (Etoposide + Cisplatin) did not significantly affect tumor growth (Fig. 6C left). LY3295668 in combination with SoC produced better-than-additive effect than either monotherapy (Fig. 6C left). In LXFS573, LY3295668 also showed significant combination benefit with SoC agents (Fig. 6C mid). In these studies, $10-15 \%$ of body weight losses were observed in combination groups. 
Multiple lines of data indicate potential synergism between Aurora A and EGFR inhibitors (35). Consequently, LY3295668 was investigated for potential synergy in combination with cetuximab and cisplatin in a Head and Neck squamous cell carcinoma (HNSCC), the Detroit 562 xenograft model (Fig. 6C right). At the end of dosing period (day-44 total duration; 4-day post dosing regimen completed), LY3295668 at $30 \mathrm{mg} / \mathrm{kg}$ alone showed significant tumor growth inhibition, so did cetuximab or cetuximab plus cisplatin treatment. More importantly, LY3295668 in combination with cetuximab or with both cetuximab plus cisplatin exhibited a synergistic effect in comparison to either monotherapy, produced much prolonged tumor growth inhibition beyond the dosing period, especially LY3295668 with cetuximab + cisplatin group (Fig. 6C right).

\section{Discussion}

Although Aurora kinases A, B and C are highly homologous, they are not functional orthologues. Aurora A-selective inhibition leads to mitotic arrest in many cancer cells. The mitotic arrest often further progresses to cancer cell apoptosis/death in sensitive cancer cell lines. We contend that an Aurora A-selective inhibitor such as LY3295668 may be more effective than Aurora B or Aurora A/B dual inhibitors (alisertib, barasertib), as it would avoid DNA endoreduplication and polyploidy, which could persist for multiple cell divisions without completely killing the cancer cells (36). A couple of Aurora A inhibitors have been identified over the years, however, they suffer either the lack of Aurora A inhibition potency or lack of enough selectivity against Aurora B (Fig. 2, and (24, 26)). LY3295668 is a potential best-in-class Aurora A inhibitor with >1,000-fold Aurora A vs Aurora B selectivity. Furthermore, we contend that at the pharmacologically relevant concentrations, LY3295668 only inhibits Aurora A in vitro and in vivo, not Aurora B. 
Using LY3295668, we discovered that Aurora A vs Aurora B/C inhibitors show profound differences in mitotic arrest phenotypes and especially apoptosis induction. While LY3295668, alisertib and barasertib each can potently inhibit HeLa cell growth, only LY3295668 consistently promoted apoptosis across the range of tested concentrations, as well as inhibits EMT and cancer cell stemness markers (Fig. 2 and 3). Interestingly, alisertib inhibits Aurora A-selectively in a range of $0.080-0.250 \mu \mathrm{mol} / \mathrm{L}$. This corresponds to the same range of concentrations needed to induce maximal apoptosis in HeLa cells. At concentrations $>0.25 \mu \mathrm{mol} / \mathrm{L}$, alisertib reduced its apoptosis induction capacity as it switched to an Aurora B-dominant phenotype (Fig. 2 and 3). So at a clinically relevant human plasma exposure of 1 to $2 \mu \mathrm{mol} / \mathrm{L}$ (37-40), alisertib behaves phenotypically as an Aurora B inhibitor in vivo (41). This phenotype has been observed previously in sarcoma cells, although alisertib showed an Aurora A inhibition phenotype (increased phospho-H3) in their model (41). While alisertib is a dual Aurora A/B inhibitor in vitro, the appearance of the Aurora B phenotype is exposure-dependent, ie., at lower plasma concentrations, only Aura A may be inhibited.

Aurora B inhibition-induced endo-reduplication and subsequent polyploidy are retinoblastoma protein-dependent and can lead to chromosome segregation errors and thus genomic instability through aberrant mitosis (Fig. 2 and 3) (17, 18, 23, 26, 42, 43). As such, Aurora B inhibitor-induced tetraploid cells, which show better survival after compound treatment (Fig. 2 and 3), could significantly increase the refractory/resistant cell population, especially when the inhibitor in vivo exposure is at sub-threshold levels during dosing intervals. Aneuploidy/Genomic instability is one of the most prevalent signatures of cancer $(44,45)$. Polyploidy, including tetraploidy, is thought to be a major pathway to induce aneuploidy and genomic instability. For example, RAS oncogene induces tetraploidy as an intermediate step in 
its tumorigenesis (46). As for cancer therapy, Aurora A selective inhibitor may be the best strategy and Aurora B activity should be avoided. LY3295668 has now advanced to Phase I clinical testing to test the translation of this hypothesis in patients (NCT03092934).

Acknowledgements We would like to thank Drs. James Starling, Alfonso de Dios, Michal

Vieth, Daphne L Farrington, Harold B Brooks, John Toth, Farhana Merzoug, Karen L Cox, Susan A Konicek, Teresa Burke for their guidance and support.

\section{Authors' contributions}

Conception and design: J. Du, R.M. Campbell, S. Buchanan, J.R. Henry, D.A. Barda, M.J.

Lallena, R. Torres, X. Gong, R.P. Beckmann, M. Marshall, L.F. Stancato, X. Ye, B. K. R. Patel, C. Reinhard, G.D. Plowman.

Development of methodology: J. Du, L. Yan, S.V. Bhagwal, R. Torres, C. Marugan, C Baquero, Y. Yang, H. Bian, X. Gong, Y. Zeng, S.M. Bogner, R.T. Foreman, A. Capen, G.P. Donoho, J. A. Dempsey, R.P. Beckmann, M. Marshall, S. Tate, L. Chio, Y. Qian, S. Chu, Y. Hui, S.

Bhattachar, L.F Stancato, M.S. Dowless, P.W. Iversen, J.R. Manro, J.L. Walgren, B.W.

Halstead, D.A. Barda, J.R. Henry, R. Martinez, M.J. Lallena, X. Ye, Reinhard1, G.D. Plowman, S. Buchanan, R.M. Campbell,

Acquisition of data: J. Du, L. Yan, R. Torres, C. Marugan, C. Baquero, Y. Yang, H. Bian, X. Gong, Y. Zeng, S.M. Bogner, R.T. Foreman, A. Capen, G.P. Donoho, J. A. Dempsey, R.D. Van Horn, D.S. Barnard, R.P. Beckmann, M. Marshall, S. Tate, L. Chio, Y. Qian, Y.W. Webster, A. Aggarwal, S. Chu, Y. Hui, S. Bhattachar, L.F Stancato, M.S. Dowless, P.W. Iversen, J.R. Manro, J.L. Walgren, B.W. Halstead, D.A. Barda, J.R. Henry, S. Buchanan, R.M. Campbell, 
Analysis and interpretation of data: P.W. Iversen, J.R. Manro, Y.W. Webster, J. Du, L. Yan, R.

Torres, C. Marugan, C Baquero, Y. Yang, H. Bian, X. Gong, Y. Zeng, S.M. Bogner, R.T.

Foreman, A. Capen, G.P. Donoho, J. A. Dempsey, R.D. Van Horn, R.P. Beckmann, M.

Marshall, S. Tate, L. Chio, Y. Qian, A. Aggarwal, S. Chu, Y. Hui, S. Bhattachar, L.F Stancato, M.S. Dowless, J.L. Walgren, B.W. Halstead, D.A. Barda, J.R. Henry, M.J. Lallena, B.K.R. Patel, S. Buchanan, R.M. Campbell,

Writing, review, and/or revision of the manuscript: J. Du, R.M. Campbell, S. Buchanan, M.J. Lallena.

\section{References}

1. Glover DM, Leibowitz MH, McLean DA, Parry H. Mutations in aurora prevent centrosome separation leading to the formation of monopolar spindles. Cell. 1995; 81:95105.

2. Bischoff JR, Plowman GD. The Aurora/IPL1 kinase family: regulators of chromosome segregation and cytokinesis. Trends Cell Biol. 1999; 9:454-9.

3. Goldenson B, Crispino JD. The aurora kinases in cell cycle and leukemia. Oncogene. 2014 Mar 17; 34:537-45.

4. Karthigeyan D, Prasad SB, Shandilya J, Agrawal S, Kundu TK. Biology of Aurora A kinase: implications in cancer manifestation and therapy. Medicinal research reviews. 2011 Sep; 31(5):757-93.

5. Bischoff JR, Anderson L, Zhu Y, Mossie K, Ng L, Souza B, et al. A homologue of Drosophila aurora kinase is oncogenic and amplified in human colorectal cancers. EMBO J. 1998; 17:3052-65. 
6. Zhou H, Kuang J, Zhong L, Kuo WL, Grey JW, Sahin A, et al. Tumor amplified kinase STK15/BTAK induces centrosome amplification, aneuploidy and transformation. Nature genetics. 1998; 20:189-93.

7. Katayama H, Zhou H, Sen S. STK15/BTAK/aurora2 kinase binding to protein phosphatase 1 is cell cycle regulated. Proc AACR; 2001; 2001. p. 1392.

8. Kufer TA, Silljé HHW, Körner R, Gruss OJ, Meraldi P, Nigg EA. Human TPX2 is required for targeting Aurora-A kinase to the spindle. J Cell Biol. 2002; 158:617-23.

9. Liu Q, Kaneko S, Yang L, Feldman, FI, Nicosia SV, Chen C, et al. Aurora-A abrogation of p53 DNA binding and transactivation activity by phosphorylation of serine-215. JBC. 2004; $279(50): 52175-82$.

10. Toji S, Yabuta N, Hosomi T, Nishihara S, Kobayashi T, Suzuki S, et al. The centrosomal protein Lats2 is a phosphorylation target of Aurora-A kinase. Genes to cells: devoted to molecular \& cellular mechanisms. 2004; 9(5):383-97.

11. Du J, Hannon GJ. Suppression of p160ROCK bypasses cell cycle arrest after AuroraA/STK15 depletion. Proc Natl Acad Sci U S A. 2004; 101:8975-80.

12. Hsu JY, Sun ZW, Li X, Beuben M, Tatchell K, Bishop DK, et al. Mitotic phosphorylation of histone $\mathrm{H} 3$ is governed by Ipl1/aurora kinase and Glc7/PP1 phosphatase in budding yeast and nematodes. Cell. 2000; 102(3):279-91.

13. Giet R, Glove DM. Drosophila aurora B kinase is required for histone H3 phosphorylation and condensin recruitment during chromosome condensation and to organize the central spindle during cytokinesis. J Cell Biol. 2001; 152:669-82.

14. Adams RR, Maiato H, Earnshaw WC, Carmena M. Essential roles of Drosophila inner centromere protein (INCENP) and aurora B in histone H3 phosphorylation, metaphase 
chromosome alignment, kinetochore disjunction, and chromosome segregation. J Cell Biol. 2001; 153(4):865-80.

15. Yasui Y, Urano T, Kawajiri A, Nagata K, Tatsuka M, Saya H, et al. Autophosphorylation of a newly identified site of Aurora-B is indispensable for cytokinesis. J Biol Chem 2004 279(13):12997-3003.

16. Sasai K, Katayama H, Stenoien DL, Fujii S, Honda R, Kimura M, et al. Aurora-C kinase is a novel chromosomal passenger protein that can complement Aurora-B kinase function in mitotic cells. Cell Motil Cytoskeleton. 2004; 59(4):249-63.

17. Hilton JF, Shapiro GI. Aurora kinase inhibition as an anticancer strategy. J Clin Oncol $2013 ; \mathbf{3 1}: 1-3$.

18. Yang H, Burke T, Dempsey J, Diaz B, Collins E, Toth J, et al. Mitotic requirement for aurora A kinase is bypassed in the absence of aurora B kinase. FEBS letters. 2005 Jun 20; 579(16):3385-91.

19. Warner SL, Munoz RM, Stafford P, Koller E, Hurley LH, Von Hoff DD, et al. Comparing Aurora A and Aurora B as molecular targets for growth inhibition of pancreatic cancer cells. Mol Cancer Ther. 2006; 5(10):2450-8.

20. Li Y, Xu FL, Lu J, Saunders WS, Prochownik EV. Widespread genomic instability mediated by a pathway involving glycoprotein Ib alpha and Aurora B kinase. J Biol Chem 2010; 285(17):13183-92.

21. Gorgun G, Calabrese E, Hideshima T, Ecsedy J, Perrone G, Mani M, et al. A novel Aurora-A kinase inhibitor MLN8237 induces cytotoxicity and cell-cycle arrest in multiple myeloma. Blood. 2010 Jun 24; 115(25):5202-13. 
22. Wilkinson RW, Odedra R, Heaton SP, Wedge SR, Keen NJ, Carfter C, et al. AZD1152, a selective inhibitor of Aurora B kinase, inhibits human tumor xenograft growth by inducing apoptosis. Clinical cancer research: an official journal of the American Association for Cancer Research. 2007 Jun 15; 13(12):3682-8.

23. Nair JS, Ho AL, Tse AN, Coward J, Cheema H, Ambrosini G, et al. Aurora B kinase regulates the postmitotic endoreduplication checkpoint via phosphorylation of the retinoblastoma protein at serine 780. Mol Biol Cell. 2009; 20(8):2218-28.

24. Nair JS, Ho AL, Schwartz GK. The induction of polyploidy or apoptosis by the Aurora A kinase inhibitor MK8745 is p53-dependent. Cell Cycle. 2012; 11(4):807-17.

25. Nair JS, Schwartz GK. MLN-8237: A dual inhibitor of aurora A and B in soft tissue sarcomas. Oncotarget. 2016; 7(11):12893-903.

26. de Groot CO, Hsia JE, Anzola JV, Motamedi A, Yoon M, Wong YL, et al. A Cell Biologist's Field Guide to Aurora Kinase Inhibitors. Front Oncol. 2015; 5(285):1-25.

27. Dickson MA, Mahoney MR, Tap WD, D'Angelo, SP, Keohan ML, Van Tine BA, et al. Phase II study of MLN8237 (Alisertib) in advanced/metastatic sarcoma. Ann Oncol. 2016; 10:1855-60.

28. Henry JR, Eli Lilly and Company. Preparation of aminopyridine compounds as Aurora A kinase inhibitors. 2017. United States patent 9637474 (Example 1).

29. Thomson S, Petti F, Sujka-Kwok I, Epstein D, Haley JD. Kinase switching in mesenchymal-like non-small cell lung cancer lines contributes to EGFR inhibitor resistance through pathway redundancy. Clin Exp Metastasis. 2008; 25(8):843-54. 
30. Patricelli MP, Szardenings AK, Liyanage M, Nomanbhoy TK, Wu M, Weissig H, et al. Functional interrogation of the kinome using nucleotide acyl phosphates. Biochemistry. 2007; 46(2):350-8.

31. Habedanck R, Stierhof YD, Wilkinson CJ, Nigg EA. The Polo kinase Plk4 functions in centriole duplication. Nature cell biology. 2005 Nov; 7(11):1140-6.

32. Ren BJ, Zhou ZW, Zhu DJ, Ju YL, Wu JH, Ouyang MZ, et al. Alisertib Induces Cell Cycle Arrest, Apoptosis, Autophagy and Suppresses EMT in HT29 and Caco-2 Cells. Int J Mol Sci. 2015; 17(1): E41.

33. Chen C, Song G, Xiang J, Zhang H, Zhao S, Zhan Y. AURKA promotes cancer metastasis by regulating epithelial-mesenchymal transition and cancer stem cell properties in hepatocellular carcinoma. Biochem Biophys Res Commun. 2017; 486(2):514-20.

34. Opyrchal M, Gil M, Salisbury JL, Goetz MP, Suman V, Degnim A, et al. Molecular targeting of the Aurora-A/SMAD5 oncogenic axis restores chemosensitivity in human breast cancer cells. Oncotarget. 2017; 8(53):91803-16.

35. Astsaturov I, Ratushny V, Sukhanova A, Einarson MB, Bagnyukova T, Zhou Y, et al. Synthetic lethal screen of an EGFR-centered network to improve targeted therapies. Science signaling. 2010; 3(140):1-18.

36. Kaestner P, Stolz A, Bastians H. Determinants for the efficiency of anticancer drugs targeting either Aurora-A or Aurora-B kinases in human colon carcinoma cells. Molecular cancer therapeutics. 2009 Jul; 8(7):2046-56.

37. Venkatakrishnan K, Zhou X, Ecsedy J, Mould DR, Liu H, Danaee H, et al. Dose selection for the investigational anticancer agent alisertib (MLN8237): Pharmacokinetics, 
pharmacodynamics, and exposure-safety relationships. Journal of clinical pharmacology. 2015 Oct 9; 55:336-47.

38. Dees EC, Cohen RB, von Mehren M, Stinchcombe TE, Liu H, Venkatakrishnan K, et al. Phase I study of aurora A kinase inhibitor MLN8237 in advanced solid tumors: safety, pharmacokinetics, pharmacodynamics, and bioavailability of two oral formulations. Clinical Cancer Research. 2012 Sep 1; 18(17):4775-84.

39. Cervantes A, Elez E, Roda D, Ecsedy J, Macarulla T, Venkatakrishnan K, et al. Phase I pharmacokinetic/pharmacodynamic study of MLN8237, an investigational, oral, selective aurora a kinase inhibitor, in patients with advanced solid tumors. Clinical Cancer Research. 2012 Sep 1; 18(17):4764-74.

40. Matulonis UA, Sharma S, Ghamande S, Gordon MS, Del Prete SA, Ray-Coquard I, et al. Phase II study of MLN8237 (alisertib), an investigational Aurora A kinase inhibitor, in patients with platinum-resistant or -refractory epithelial ovarian, fallopian tube, or primary peritoneal carcinoma. Gynecologic oncology. 2012 Oct; 127(1):63-9.

41. Dickson MA, Mahoney MR, Tap WD, D'Angelo, SP, Keohan ML, Van Tine BA, et al. Phase II study of MLN8237 (Alisertib) in advanced/metastatic sarcoma. Annals of Oncology. 2016; 27:1855-60.

42. Oser MG, Fonseca R, Chakraborty AA, Brough R, Spektor A, Jennings RB, et al. Cells Lacking the RB1 Tumor Suppressor Gene are Hyperdependent on Aurora B Kinase for Survival. Cancer Discovery. 2019; 9: 230-247.

43. Gong X, Du J, Parsons SH, Merzoug FF, Webster Y, Iversen PW, et al. Aurora-A kinase inhibition is synthetic lethal with loss of the RB1 tumor suppressor gene. Cancer Discovery. 2019; 9: 248-263. 
Author Manuscript Published OnlineFirst on September 17, 2019; DOI: 10.1158/1535-7163.MCT-18-0529

Author manuscripts have been peer reviewed and accepted for publication but have not yet been edited.

44. Hanahan D, Weinberg RA. Hallmarks of cancer: the next generation. Cell. 2011 Mar 4; 144(5):646-74.

45. Storchova Z, Kuffer C. The consequences of tetraploidy and aneuploidy. Journal of cell science. 2008; 121:3859-66.

46. Zeng X, Shaikh FY, Harrison MK, Adon AM, Trimboli, AJ, Carroll KA, et al. The Ras oncogene signals centrosome amplification in mammary epithelial cells through cyclin D1/Cdk4 and Nek2. Oncogene. 2010 Sep 9; 29(36):5103-12. 


\section{Figure legends}

Figure 1. LY3295668 is a potent and highly selective Aurora A inhibitor. A: LY3295668 chemical structure. B: Kinase binding profile from DiscoverX. All kinases with $\mathrm{IC}_{50}$ less than 1 $\mu \mathrm{mol} / \mathrm{L}$ are listed. C: LY3295668 dose response curves on Aurora A, Aurora B enzymatic (left), cell (middle) inhibitions and mitotic phenotypic (right) profile. Enzymatically, AurA inhibition $\mathrm{IC}_{50} 0.00112 \pm 0.000148 \mu \mathrm{mol} / \mathrm{L}(\mathrm{n}=4, \boldsymbol{\varpi}) ;$ AurB IC $\mathrm{I}_{50} 1.51 \pm 0.668 \mu \mathrm{mol} / \mathrm{L}(\mathrm{n}=5, \circ)$. In cells, AurA inhibition $\mathrm{IC}_{50} 0.00059 \pm 0.000784 \mu \mathrm{mol} / \mathrm{L}(\mathrm{n}=4, \mathbf{\square}) ; \mathrm{IC}_{90}$ of $0.00623 \pm 0.00318 \mu \mathrm{mol} / \mathrm{L}$ $(\mathrm{n}=4, \mathbf{\square})$; and AurB inhibition $\mathrm{IC}_{50} 1.42 \pm 0.416 \mu \mathrm{mol} / \mathrm{L}(\mathrm{n}=4, \circ)$. Mitotic index $(\mathrm{MI})(\mathrm{P}-\mathrm{H} 3$ increase) $\mathrm{IC}_{50} 0.108 \pm 0.015 \mu \mathrm{mol} / \mathrm{L}(\mathrm{n}=4$, $\mathbf{\square}$ on left $\mathrm{Y}$-axis); G2/M arrest (4N DNA content increase) $\mathrm{IC}_{50} 0.108 \pm 0.027 \mu \mathrm{mol} / \mathrm{L}\left(\mathrm{n}=4, \Delta\right.$ on left $\mathrm{Y}$-axis); and cell growth inhibition $\mathrm{IC}_{50}$ $0.053 \pm 0.012 \mu \mathrm{mol} / \mathrm{L}(\mathrm{n}=4, \circ$ on right $\mathrm{Y}$-axis). D: Multiple regression analysis for Aurora A (left), B (middle) and mitotic arrest (right) cell phenotype potency (on 448, 435, and 627 SAR cpds with available data points, respectively) with Aurora A and B enzymatic activity correlation.

Figure 2. LY3295668 selective Aurora A inhibition leads to most significant apoptosis in HeLa cells. A: In comparison of alisertib and barasertib, LY3295668 showed the most persistent Aurora A inhibition induced mitotic arrest. LY3295668 cell potency is listed in Fig. 1C (middle panel). Alisertib showed AurA cell $\mathrm{IC}_{50} 0.004 \pm 0.004 \mu \mathrm{mol} / \mathrm{L}(\mathrm{n}=5) ;$ AurB cell $\mathrm{IC}_{50} 0.051 \pm 0.010$ $\mu \mathrm{mol} / \mathrm{L}(\mathrm{n}=7)$; and Mitotic index (MI) (P-H3 increase) $\mathrm{IC}_{50} 0.066 \pm 0.039 \mu \mathrm{mol} / \mathrm{L}(\mathrm{n}=7)$. Barasertib exhibited AurA cell IC50 >20 $\mu \mathrm{mol} / \mathrm{L}$; AurB cell $\mathrm{IC}_{50} 0.011 \pm 0.006 \mu \mathrm{mol} / \mathrm{L}(\mathrm{n}=11)$; and Mitotic index (MI) (P-H3 increase) $\mathrm{IC}_{50} 0.022 \pm 0.007 \mu \mathrm{mol} / \mathrm{L}(\mathrm{n}=4) . \mathrm{B}: \mathrm{LY} 3295668$, alisertib and barasertib cell proliferation inhibition (left) and apoptosis induction (CASP3/7, right) in 
Incucyte assay. Each square represents the cell confluency or the CASP3/7 positive green dot numbers (Y-axis) in the cell culture well from 0 to 48 -hour (X-axis). The percentage of cell growth or apoptosis positive cell numbers is plotted below.

Figure 3. LY3295668 Aurora A inhibition induced mitotic arrest leads to apoptosis, not polyploidy. A: Immunofluorescent staining on mitotic spindle ( $\beta$-tubulin), Aurora A, Aurora PThr288, histone H3 P-Ser10, and Centrin 1 localization on Hela cells treated with $1 \mu \mathrm{mol} / \mathrm{L}$ of LY3295668, alisertib, or barasertib for 24 hours. B: Quantification of P-Aurora A and P-H3 inhibition by the Aurora inhibitors from 3 repeated immunofluorescence experiments. Statistical significance is indicated by $* * *(p<0.001)$. C: Western on mitotic and apoptosis markers with HeLa cells treated by indicated Aurora inhibitors for 24 (left) and 48 (right) hours. D: Western on mesenchymal marker E-cadherin and stemness marker Sox2 in NCI-H358 cells. E: DNA histogram by flow cytometry on mitotic arrest and tetraploidy induction from indicated Aurora inhibitor treatment. HeLa cells were treated with $1 \mu \mathrm{mol} / \mathrm{L}$ of each compound for 24 (upper panel) or 48 (lower panel) hours.

Figure 4. LY3295668 shows potent cell viability inhibition in a large panel of cancer cells. A: Waterfall plot of LY3295668 cell viability inhibition potency $\log \left(\mathrm{IC}_{50}\right)$. The cell lines are indicated at the bottom of the plot. B: LY3295668 cell viability inhibition potency $\log \left(\mathrm{IC}_{50}\right)$ in breast cancer cell line sub-panel. C: LY3295668 Log( $\left.\mathrm{IC}_{50}\right)$ in lung cancer cell line sub-panel. The cells at exponent growth phase were treated with LY3295668 for two doubling time and the cell viability inhibition was measured by CellTiter Glo (CTG) assay.

Figure 5. LY3295668 inhibits Aurora A in vivo. A: In mouse and rat NCI-H446 xenograft models, animals were treated with LY3295668 at indicated doses for 3 hours. Aurora A P-Thr288 
inhibition in tumors ( $\square$ Y-axis at left) and compound exposure in animal plasma ( $\circ$ Y-axis on right) were measured. B: Animals were treated with LY3295668 once. At indicated time points,

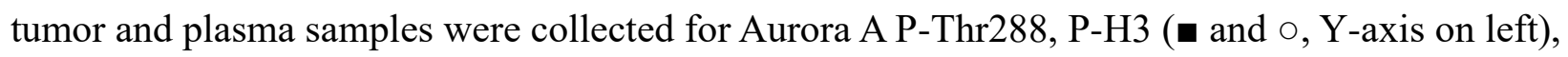
and compound exposure ( $\square \mathrm{Y}$-axis on right). TED 50 : Threshold Effective Dose (dose that produces an effect that equals to $50 \%$ P-Aurora A inhibition). TEC $_{50}$ : Threshold Effective Concentration (plasma concentration that produces an effect that equals to $50 \% \mathrm{P}$-Aurora $\mathrm{A}$ inhibition).

Figure 6. LY3295668 is efficacious in preclinical tumor models. A: LY3295668 was dosed at indicated doses and durations with NCI-H446 (left) and NCI-H69 (middle and right) models. The dosing durations for each treatment is indicated by the red line (left) and lines color coded to match the dosing schedules (middle and right). At the indicated time (red arrow), the average tumor growth inhibitions for each treatment group are plotted in the insert. B: LY3295668 efficacy with SCLC PDX models. LY3295668 was dosed at $50 \mathrm{mg} / \mathrm{kg}$ by oral (P.O.) BID for 28 days, while the Standard-of-Care was dosed with etoposide $30 \mathrm{mg} / \mathrm{kg}$ subcutaneously (S.C.) Q7Dx4 plus cisplatin $3.2 \mathrm{mg} / \mathrm{kg}$ S.C. Q7Dx4. The dosing duration is indicated by the red line. C: LY3295668 in combination with SoC showed better efficacy in SCLC PDX and Head and Neck xenograft models. For LXFS 2156 and 573 SCLC PDX models, LY3295668 was dosed at 40 $\mathrm{mg} / \mathrm{kg}$ P.O. for 28 days. SoC was etoposide at $30 \mathrm{mg} / \mathrm{kg}$ S.C. Q7Dx3 plus cisplatin $3.2 \mathrm{mg} / \mathrm{kg}$ S.C. Q7Dx3. For Detroit 562 xenograft model, LY3295668 was dose at $30 \mathrm{mg} / \mathrm{kg}$ P.O. BID for 28 days. Cisplatin was used at $4 \mathrm{mg} / \mathrm{kg}$ Q7Dx4 and cetuximab was at $20 \mathrm{mg} / \mathrm{kg}$ twice-a-week (BIW)x4. The dosing duration is indicated by the red line. The insert plot of tumor response rates at the measured time point are indicated by the red arrow, and the statistical significance is indicated by the $\mathrm{p}$ value. 
Figure 1.

A<smiles>Cc1cc(Nc2ccc(F)c(C[C@@]3(C(=O)O)CCN(Cc4cccc(Cl)c4F)[C@@H](C)C3)n2)n[nH]1</smiles>

B

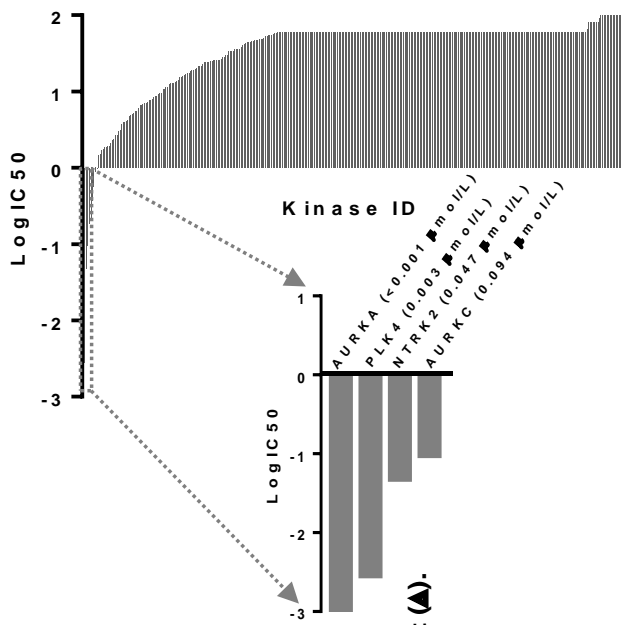

Biochemical activity

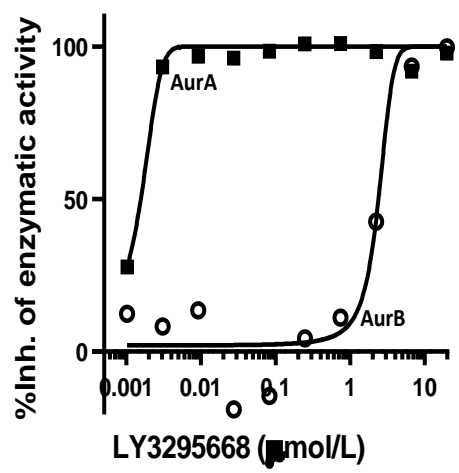

D

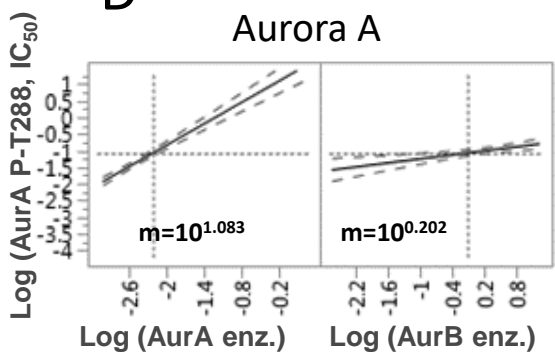

Term Estimate SE P $>$ It

$\begin{array}{llll}\text { Intercept } & 1.347 & 0.203<0.0001\end{array}$

Log Aurora A $1.083 \quad 0.083<0.0001$

Log Aurora B

$\begin{array}{lll}0.202 & 0.092 & 0.0009\end{array}$

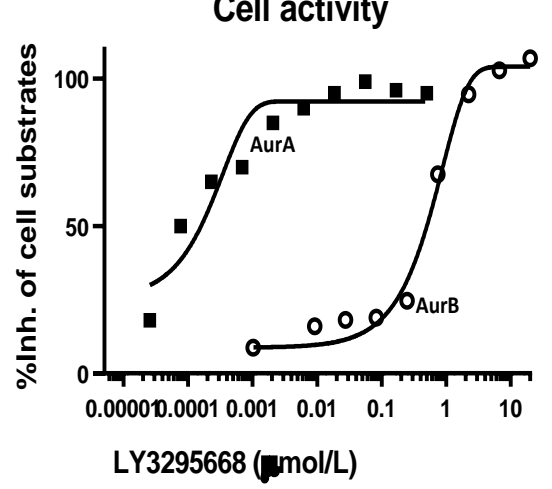

응

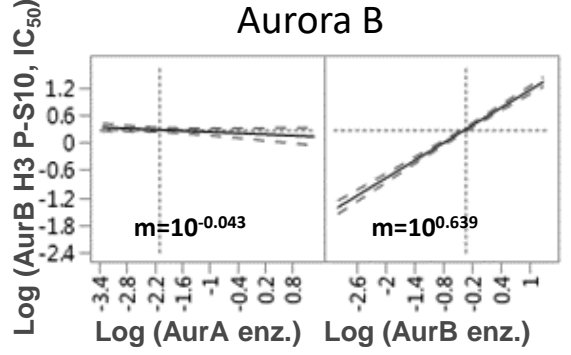

Term Estimate SE $\mathbf{P}>\mid \mathbf{t |}$

$\begin{array}{llll}\text { Intercept } & 0.408 & 0.063<0.0001\end{array}$

$\begin{array}{llll}\text { Log Aurora A } & -0.043 & 0.028 & 0.1241\end{array}$

Log Aurora B
:

Mitotic phenotype and growth inh.
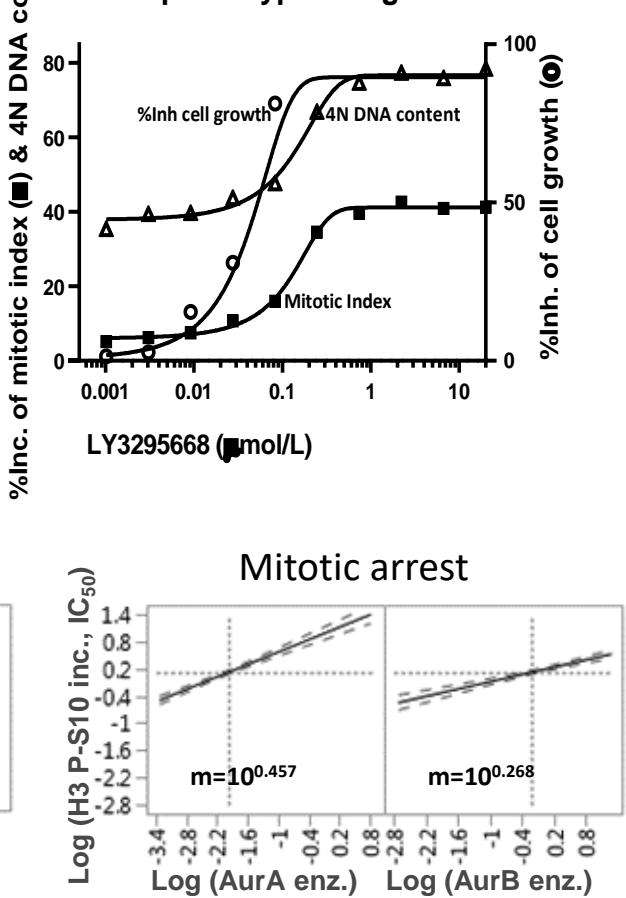

Term Estimate SE P $>$ It

$\begin{array}{llll}\text { Intercept } & 1.084 & 0.071<0.0001\end{array}$

$\begin{array}{llll}\text { Log Aurora A } & 0.457 & 0.033<0.0001\end{array}$

Log Aurora B $0.268 \quad 0.031<0.0001$ 
Figure 2.

A
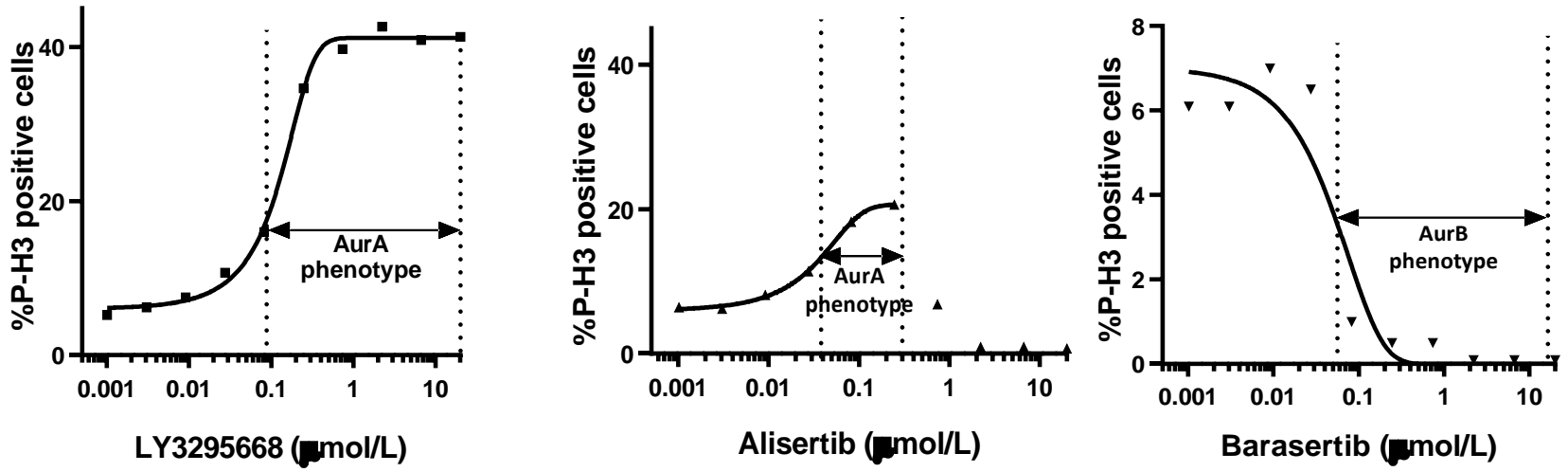

B

Cell growth
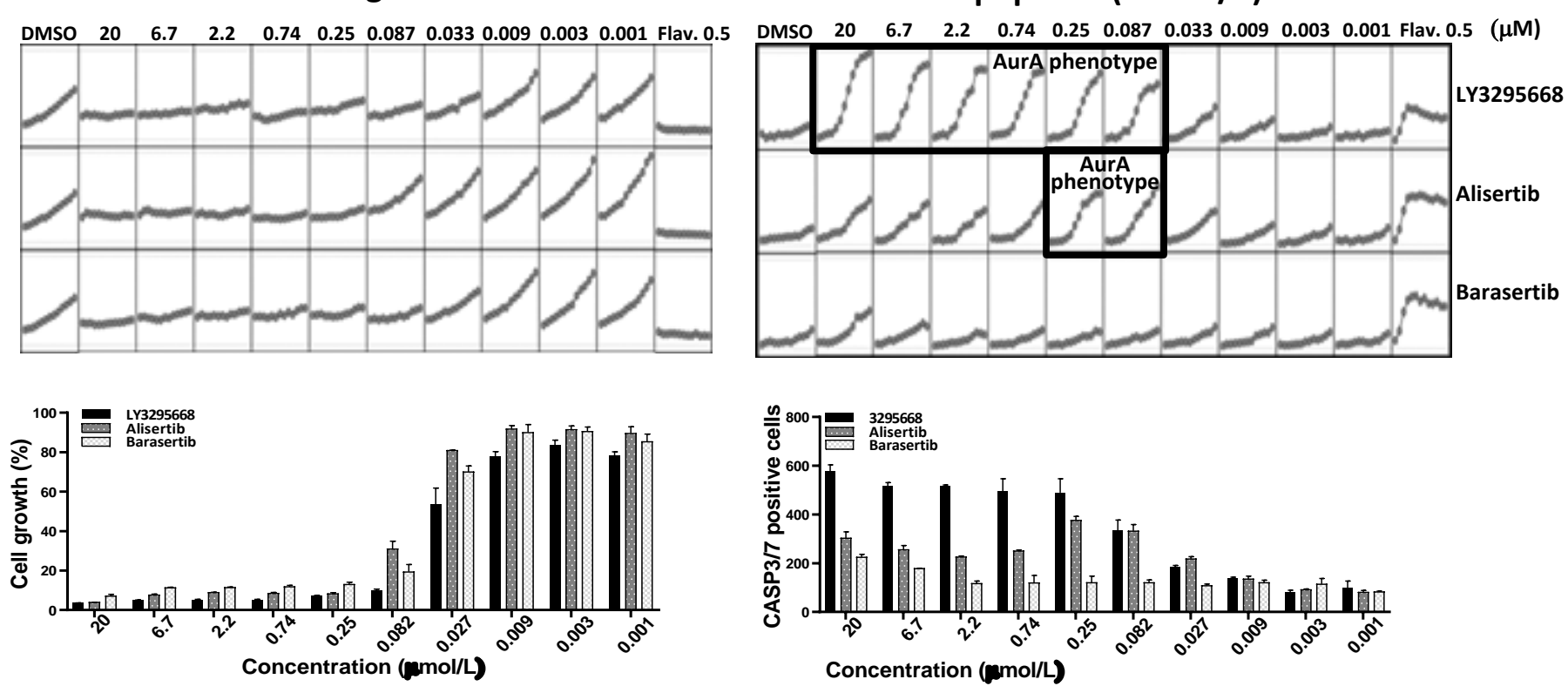


\section{Figure 3.}

\section{A}
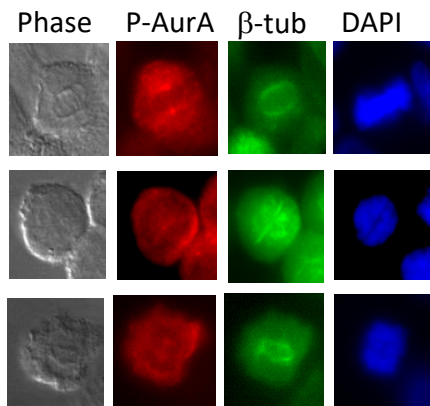

Merge
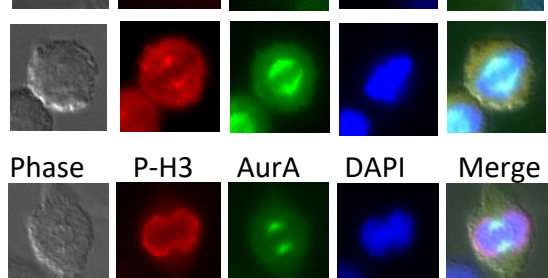

DAPI
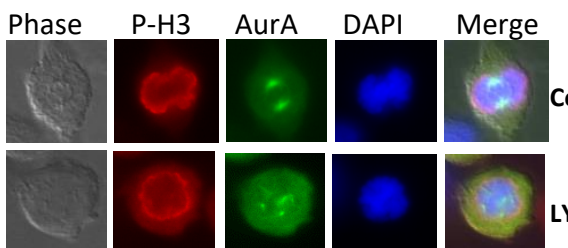

Control
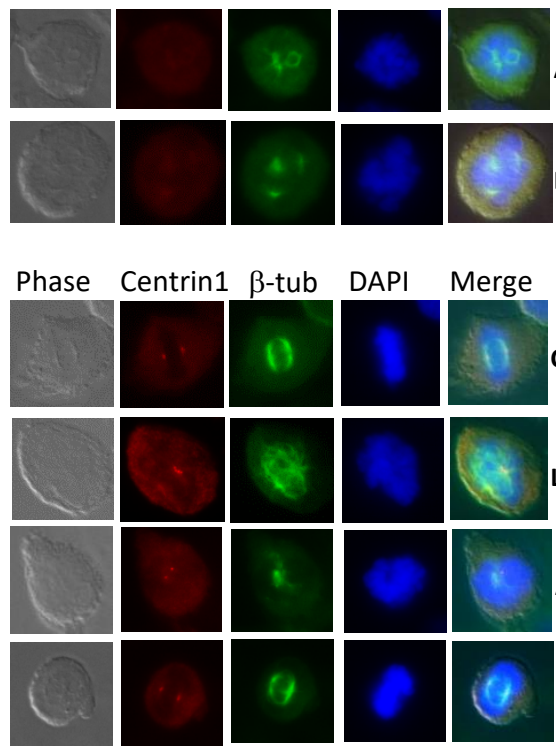

$\mathrm{B}$

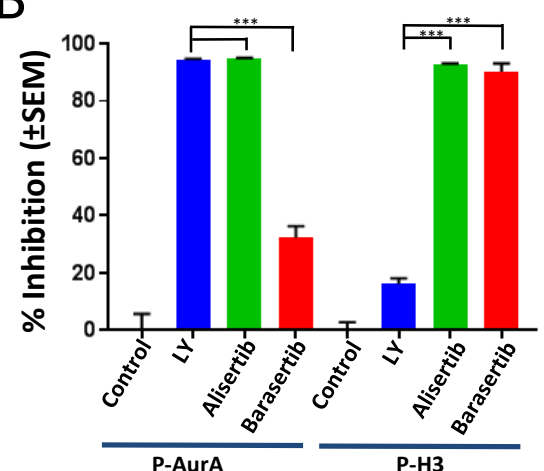
Barasertib

$24 \mathrm{hrs}$

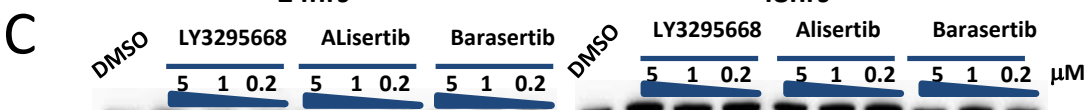

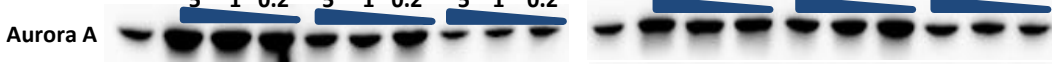

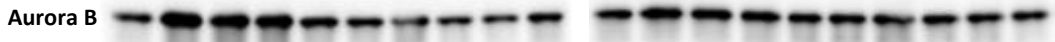
H3 P-S10

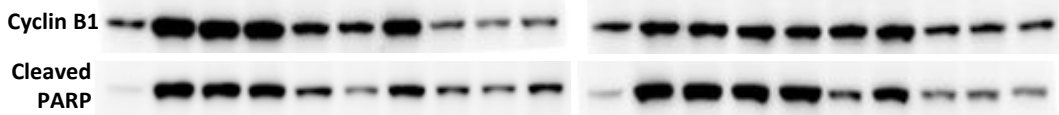
$\alpha$-Tubulin LY3295668

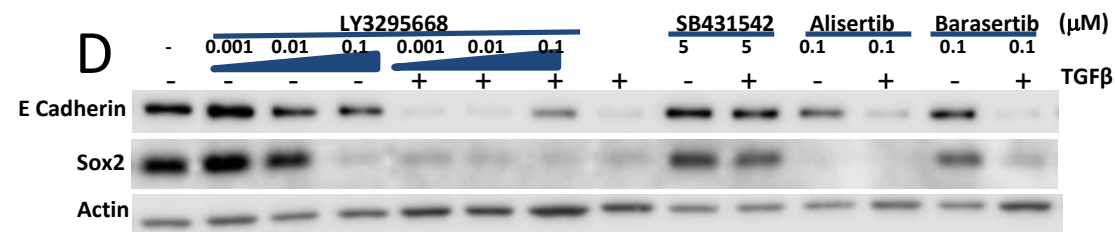

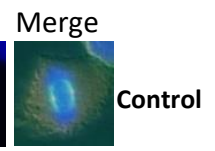

E DMSO Barasertib

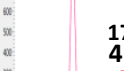

$17 \%$
$4 N$
7
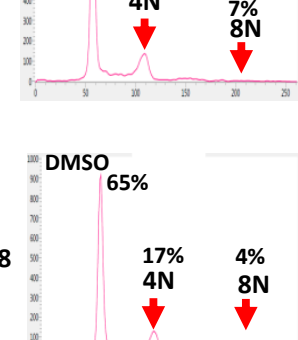

Alisertib

LY3295668
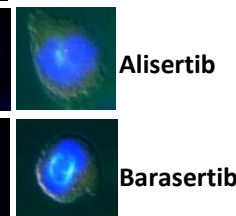

$24 \mathrm{hrs}$

LY3295668 $\quad$ Alisertib

$48 \mathrm{hrs}$

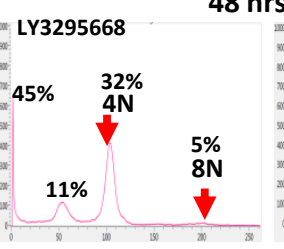

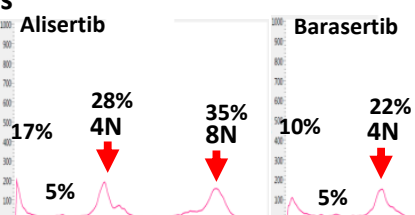


Figure 4.

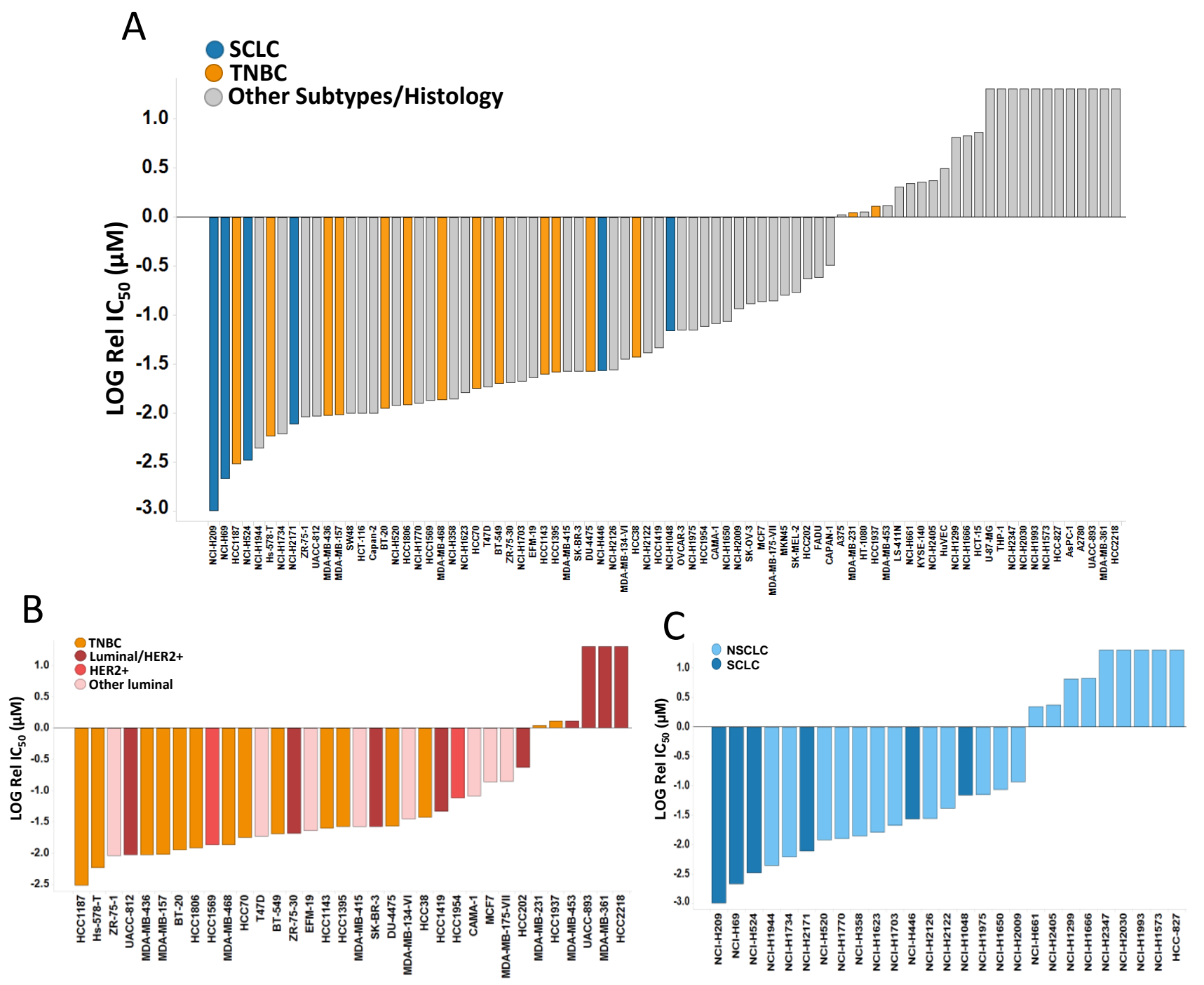


Figure 5.

A

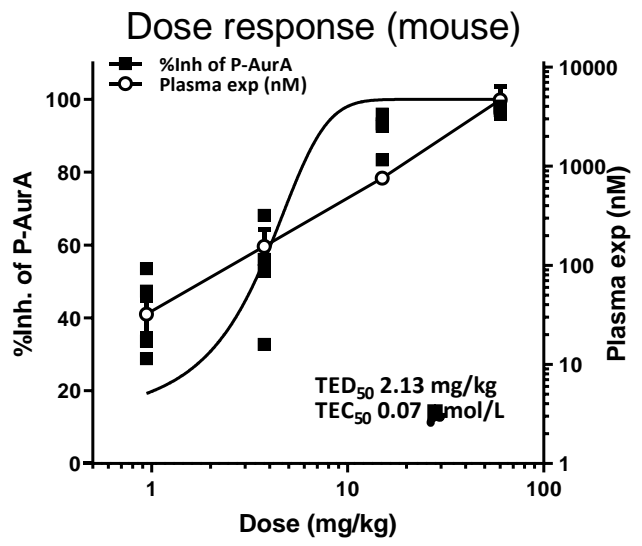

B

Time course (30 mg/kg, mouse)
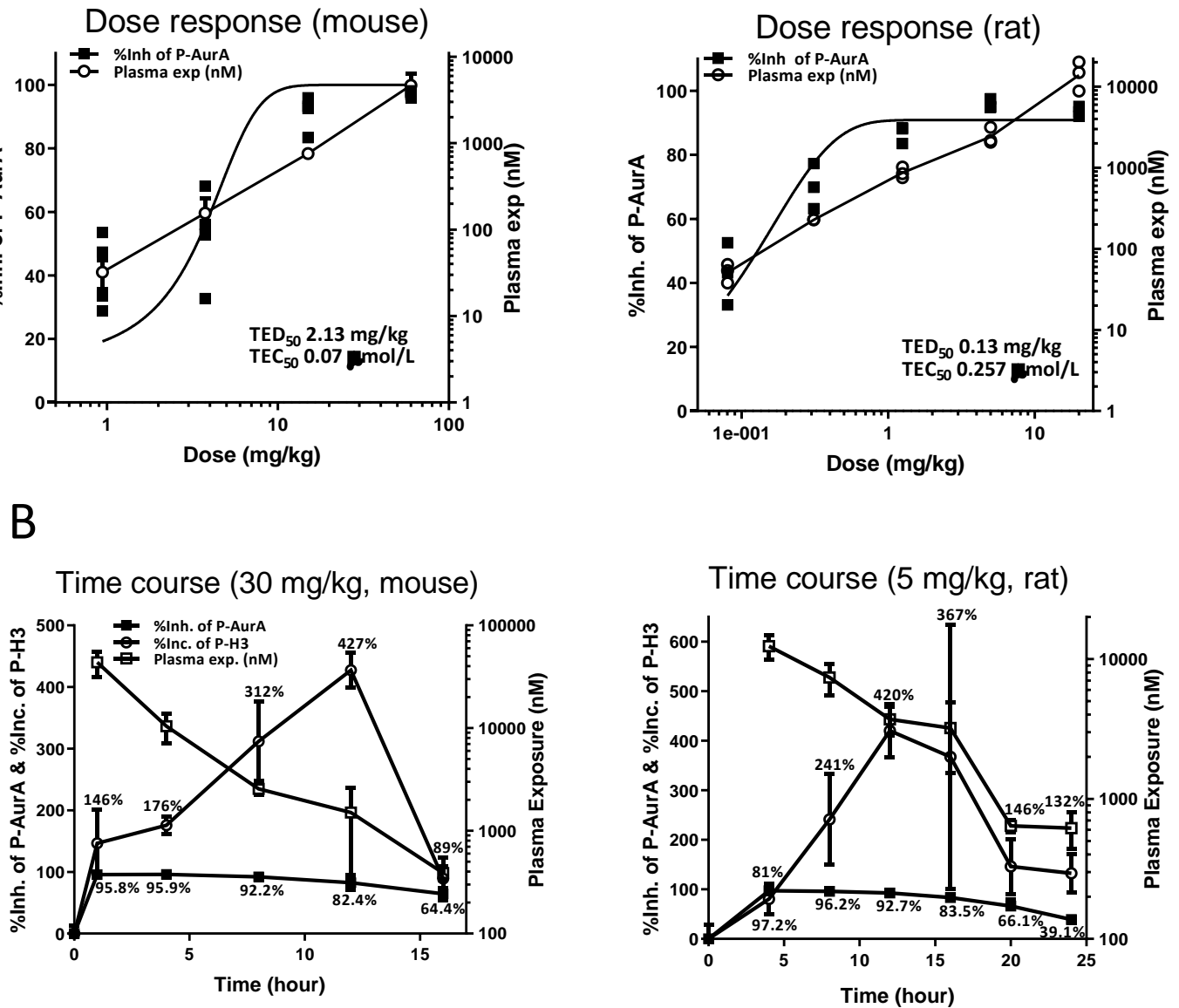

Time course $(5 \mathrm{mg} / \mathrm{kg}$, rat)

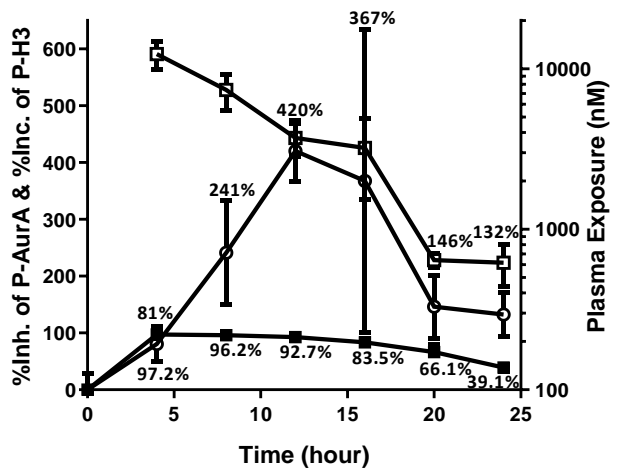


Figure 6.
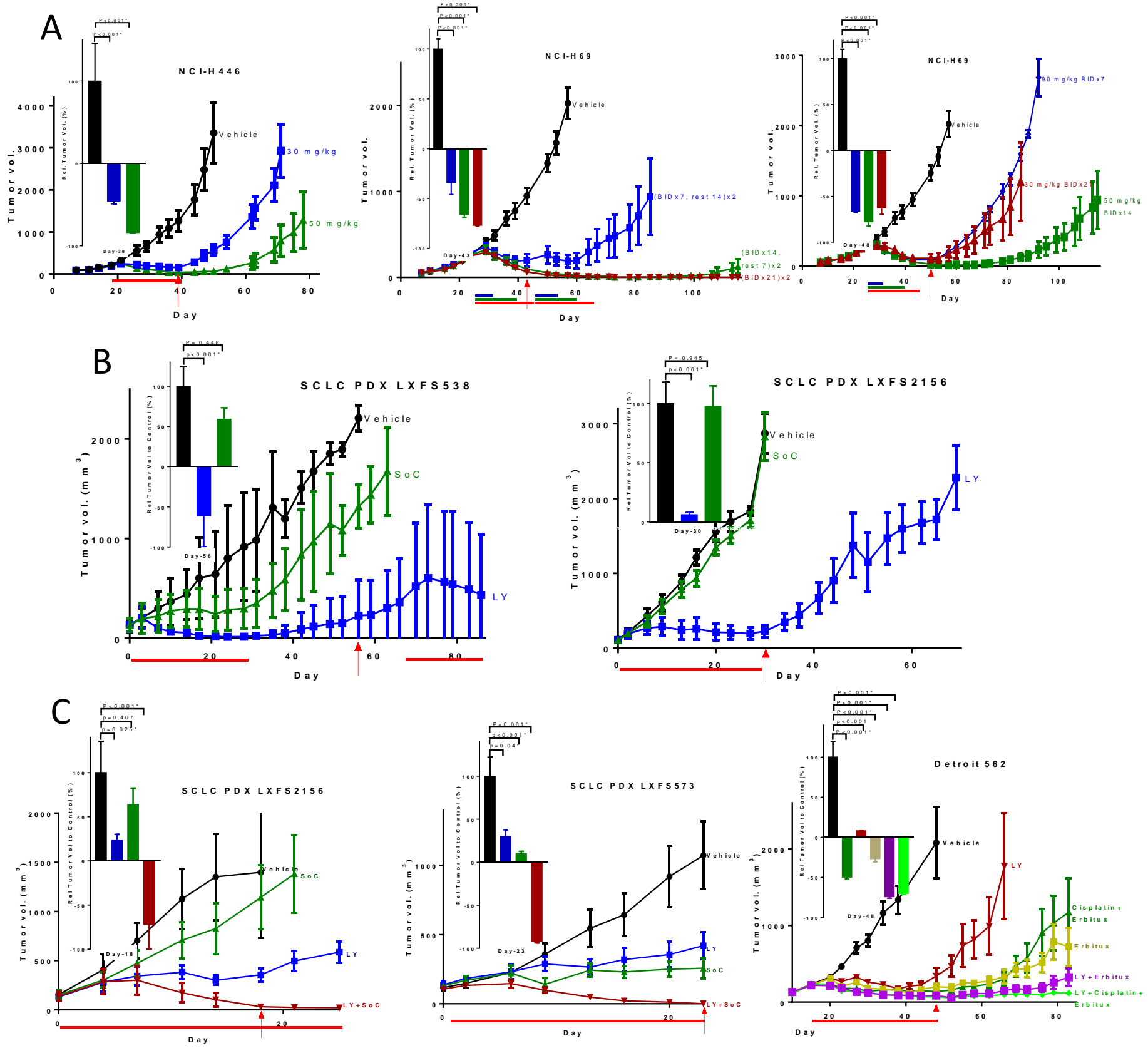